\title{
Young Belugas Diversify Adult Beluga (Delphinapterus leucas) Behavior
}

\author{
Heather Hill ${ }^{1}$, Sara Guarino ${ }^{1}$, Shirlee Crandall ${ }^{2}$, Emily Lenhart ${ }^{1}$, \& Sarah Dietrich $^{3}$ \\ ${ }^{1}$ St. Mary's University \\ ${ }^{2}$ SeaWorld San Antonio \\ ${ }^{3}$ University at Buffalo, State University of New York \\ *Corresponding author (Email: hhill1@ stmarytx.edu)
}

Citation - Hill, H., Guarino, S., Crandall, S., Lenhart, E., \& Dietrich, S. (2015). Young belugas diversify adult beluga (Delphinapterus leucas) behavior. Animal Behavior and Cognition, 2(3), 267-284. doi: 10.12966/abc.08.06.2015

\begin{abstract}
Across the animal kingdom, immature animals are characterized by their playfulness and diversity of behavior, but are their actions enriching to adult conspecifics? The purpose of this study was to assess if beluga (Delphinapterus leucas) calves influenced the behavioral repertoire of adult conspecifics, specifically with regard to play behaviors, social interactions, and solitary swimming. Video recordings made between 2012 and 2015 (200+ hrs) were randomly selected using the following social groupings: adults only $(n=13)$, adults with juvenile $(n=28)$, mother-calf pairs $(n=24)$, mother-calf pairs with juvenile $(n=26)$, and mixed groups $(n=84)$ that included different ages and sexes. Each recording was coded using a 1-min instantaneous sampling method for 7 behavioral categories that were grouped into 4 major categories: mother-calf swim, social interactions, play, and solitary swims. Results indicated that the social grouping influenced the behavioral categories even when number of animals in the social grouping was controlled. Adults displayed solitary swims significantly $(p<0.001)$ more often when grouped with each other (adjusted $M=86 \%$ ) or with juvenile belugas (adjusted $M=85 \%$ ) than any other combination in which calves were present (adjusted $M$ ranged between $42 \%-64 \%)$. The presence of calves also significantly $(p=0.002)$ increased the number of play activities observed for adults (Adults only: adjusted $M<0 \%$; Mixed: adjusted $M=11 \%$ ). The percent of social interactions did not significantly $(p=0.196)$ change across the different social groupings. The results demonstrate that the presence of beluga calves decreased the percent of time adults spent in solitary swims and increased the percent of time adults spent in other activities, including play behaviors and social interactions. The presence of beluga calves is associated with increased diversity of the behavioral repertoires of adult conspecifics.
\end{abstract}

Keywords - Beluga, Delphinapterus leucas, Enrichment, Play, Social composition, Social interactions, White whale

The consideration and scientific study of the physical and psychological welfare of captive animals has increased steadily over the last 30 years (de Azevedo, Cipreste, \& Young, 2007; Mason, 2010; Walker, Díez-León, \& Mason, 2014). One effort used to enhance captive animal welfare is environmental enrichment, which refers to the modification of the proximate surroundings of captive animals (e.g., Held \& Spinka, 2011; Newberry, 1995; Shepherdson, Mellen, \& Hutchins, 1998). The movement for environmental enrichment has changed formerly sterile captive housing and social groupings to more stimulating and species-appropriate environments. Enrichment has been achieved through a broad range of techniques that include the incorporation of more naturalistic features (e.g., plants and trees), sensory stimulation (e.g., odors and sounds of natural prey or natural habitat), the addition of novel objects (e.g., card board boxes and balls) and complex structures that allow animals to increase their ranges and utilize their natural behaviors (e.g., jungle gyms for primates and elevated walkways for big cats), and training or controlled interactions with humans (Melfi, 2013; Newberry, 1995; Swaisgood \& Shepherdson, 2005; 
Wells, 2009). A number of studies have validated the benefits of living in enriched environments, including changes in neural anatomy, increased reproduction, lower levels of stress hormones, decreased time exhibiting stereotypies, increased exploration and play, increased affiliative social interactions, and more species-typical behaviors (Held \& Spinka, 2011; Mason, 2010; Newberry, 1995; Swaisgood et al., 2001; Swaisgood \& Shepherdson, 2005, 2006; Wells, 2009).

While environmental enrichment encompasses a broad array of options, research on enrichment efforts has mainly focused on the modification of inanimate aspects of the environment, varied feeding routines, providing sensory stimulation, and training (Carlstead \& Shepherdson, 1994; Held \& Spinka, 2011; Melfi, 2013; Newberry, 1995; Shyne, 2006; Swaisgood \& Shepherdson, 2005, 2006; Wells, 2009). In contrast, the influence of social composition as an enrichment technique has not been examined consistently across many taxa, centered exclusively on laboratory animals, such as primates and rodents (Boere, 2001; Hutchinson, Avery, \& VandeWoude, 2005; Schapiro, Bloomsmith, Suarez, \& Porter, 1996).

Research dating back to the classic social deprivation studies with rhesus macaques (Macaca macaca) by Harlow and Harlow (1962) has consistently supported that social species in captivity are best raised and housed with other conspecifics (Boere, 2001; Held \& Spinka, 2011; Hutchinson et al., 2005; Schapiro et al., 1996). Offspring develop more complex and species-typical behaviors when reared with their mothers and are part of larger mother-offspring social groupings, when appropriate for the species (Boere, 2001; Carlstead \& Shepherdson, 1994; Harlow \& Harlow, 1962; Hutchinson et al., 2005; Schapiro et al., 1996). Limited research exists on the influence of offspring and young animals toward the mother or other conspecifics. As an example, results of a study with captive adult squirrel monkeys (Saimiri sciureus) demonstrated that housing immature offspring with adults produced increased levels of stress and reduced affiliative adult-adult interactions; a trend that reversed when the immature offspring were separated from the adults. The authors suggested that the constant play attempts by the offspring towards the adults were stress-inducing and disruptive to adult interactions (Soltis, Wegner, \& Newman, 2003).

When enriching, social groupings diversify the behavioral repertoires of individual animals by promoting different types of behaviors, including social interactions and play activities. However, optimal housing and rearing conditions are dependent on a number of factors, including animal density, habitat size, age of animals, sex ratio, dominance hierarchies, and species-specific sociality (Boere, 2001; Held \& Spinka, 2011; Hutchinson et al., 2005; Schapiro et al., 1996). Previous research has reported deleterious effects when animals are housed in large social groupings with little space (Boere, 2001; Carlstead \& Shephedson, 1994; Harlow \& Harlow, 1962; Hutchinson et al., 2005; Schapiro et al., 1996). Inappropriate sex ratios and disruption of dominance hierarchies may increase stress depending on reproductive receptivity, dominance struggles, or other agonistic responses (Boere, 2001; Hutchinson et al., 2005; Schapiro et al., 1996). However, as illustrated by research with western gorillas (Gorilla gorilla gorilla), when captive groupings can simulate naturalistic social groupings (including mixed sex/age and bachelor herds for the gorillas), species-typical behaviors and affiliative social interactions are exhibited (Stoinski, Kuhar, Lukas, \& Maple, 2004a, 2004b; Stoinski, Lukas, \& Kuhar, 2013).

Increasing evidence suggests that play is contagious in many species (reviewed by Held \& Spinka, 2011) even for adults that generally do not engage in play (Burghardt, 2005). In some species, the play behavior of one animal can generate play in the population, a phenomenon known as social amplification (Held \& Spinka, 2011). Increased play, although not a definitive indicator of welfare, can lead to substantial health benefits (Held \& Spinka, 2011). Attempts to generate social amplification of play include introducing pre-recorded play vocalizations (Knutson, Burgdorf, \& Panksepp, 1998) and training (Held \& Spinka, 2011). Appropriately including immature animals in social groupings is a yet-unexplored avenue for social amplification of play. A rich body of research with a variety of animals clearly indicates that young conspecifics are energetic, playful, curious, creative, and sociable (reviews: Bekoff \& Byers, 1998; Burghardt, 2005, 2013; Held \& Spinka, 2011). If immature animals increase affiliative interactions, play, or general activities within a population and decrease stereotyped behaviors, then the addition of immature animals would act as enrichment to the population.

Although many difficulties lie in measuring the effects of different forms of enrichment; much of the research on environmental enrichment has targeted diversifying the behavioral repertoire of individuals, 
rather than the group as a whole (Mason, 2010; Swaisgood \& Shepherdson, 2005, 2006; Wells, 2009). This tendency to focus on individuals has been applied to charismatic terrestrial megafauna, such as felids and ursids housed in zoos, as well as less charismatic groups, such as reptiles and amphibians (Burghardt, 2013; Hayes, Jennings, \& Mellen, 1998). In contrast to this individual approach, the welfare of farm animals has been measured at a group level (Walker et al., 2014). Population-level analyses of welfare have become more common in the zoo community after a seminal paper called for an epidemiological approach to welfare research (Millman, Johnson, O'Connor, \& Zanella, 2009). Leading this movement, Carlstead, Mench, Meehan, and Brown (2013) have developed "benchmark" comparisons through a variety of animal-based measures across the majority of zoo populations of African and Asian elephants. While measures of fertility, stillbirths, infant mortality, and survivorship are important indicators of general welfare, recent research has stressed the importance of assessing the behavior-based activity budgets at both the population-level and individual-level of captive elephants. In particular, using real-time observations of the elephant population or keeper-surveys, the proportion of stereotypic behavior represented by the population of elephants may be a more accurate reflection of elephant welfare than individual-animal based results (Clubb \& Mason, 2002; Mason \& Veasey, 2010).

As two highly charismatic mammals with similarities in their life histories and sociality, elephants and cetaceans, have often been compared (e.g., Connor, 2002). Interestingly, only a handful of published, peer-reviewed empirical studies on the impact of enrichment for marine mammals (e.g., cetaceans) have been conducted (e.g., Castellote \& Fossa, 2006; Clark, 2013; Harley, Fellner, \& Stamper, 2010; Hunter, Bay, Martin, \& Hatfield, 2002; Kastelein, Postma, \& Jennings, 2007; Kuczaj et al., 2002; Smith \& Litchfield, 2010). Instead, the majority of the research on the effects of environmental enrichment has been shared only inside of the marine mammal training field through an annual meeting and a quarterly periodical, Soundings, sponsored by the International Marine Animal Trainers Association (IMATA; Brando, 2010). As the debate about maintaining marine mammals in captivity grows, the field must respond in kind. Inspired by the need to study the impact of environmental enrichment on captive marine mammals, we decided to examine the impact of social groupings on the spontaneous behaviors of a group of belugas (Delphinapterus leucas) in human care, retrospectively.

The purpose of the present study was to determine whether or not the presence of young beluga whales could enrich the behavioral repertoire of adult belugas (as measured by the presence of play, stereotypic behaviors, or social interactions). Although adult delphinids and whales do not engage in as much play behavior as immature conspecifics, adults do play whether they are in human care or their natural habitat (dolphins, Tursiops sp. \& Stenella sp.: Greene, Mellilo-Sweeting, \& Dudzinski, 2011; Herzing, 2005; Kuczaj, Makecha, Trone, Paulos, \& Ramos, 2006; belugas: Hill \& Ramirez, 2014). In fact, some adults will imitate young conspecifics (e.g., bottlenose dolphins, Tursiops truncatus, Kuczaj et al., 2006). Typically though, bottlenose dolphin calves prefer to play with and imitate the behavior of same-aged peers and adults (Greene et al., 2011; Kuczaj et al., 2006; Mackey, Makecha, \& Kuczaj, 2014). Research on stereotypic behaviors, such as pacing in felids, has not been conducted specifically with delphinds and whales in human care. However, swim patterns do emerge during periods of rest and solitary or pair swimming (e.g., Hill, Carder, \& Ridgway, 2009; Sekiguchi, Arai, \& Kohshima, 2006; Stafne \& Menger, 2004). While samples sizes are often limited in many of the marine mammal studies, much of the behavioral research is conducted on group trends in addition to individual responses. This approach in marine mammal research corresponds to the population-level analysis found in the elephant welfare literature (Clubb \& Mason, 2002; Mason \& Veasey, 2010; Whitham \& Wielebnowski, 2013).

To assess the possibility that young belugas may enrich the behavioral repertoire of a group of adult belugas, we selected video recordings representing specific types of social groupings from 200+ hours of archived video footage collected across a three-year period $(2012-2015)$, which represented part of a longitudinal study of beluga behavioral development with a group of $8-10$ belugas in human care. This long-term study, originating in 2007, has produced over $500 \mathrm{hrs}$ of video footage of male and female belugas ranging in age from birth to over 30 years. Although retrospective in nature, this study represents the first examination of the influence of social composition on the general group activities of belugas in human care. Many studies of environmental enrichment evaluate its impact by measuring the diversity of a 
behavioral repertoire of an individual or the promotion of species-typical behavior; the current study deviates from this norm. Although individual belugas were expected to respond differently to the presence of young belugas, we were most interested in determining if social composition of a group would affect several broad behaviors that were part of the belugas' natural behavioral repertoire: solitary swimming, play behavior, and social interactions. We expected 1) less solitary swimming by adults when grouped with calves or immature belugas than when grouped with each other; 2) more play behaviors and social interactions by adults when grouped with calves or immature belugas than when grouped together; and 3) increased behavioral diversity, as measured by percentage of time in non-swim behaviors, of adults in the presence of young belugas than when grouped together.

\section{Subjects}

\section{Method}

Ten belugas (Delphinapterus leucas) co-housed at a single facility comprise the subjects for this study and included five adults (four females and one male), three juveniles (4 - 7 years), one male and two females, and two unweaned calves (birth -2 years), one female and one male. Table 1 summarizes sex, age, and number of sessions for each beluga. This population had varying access to seven different pools containing more than two million gallons of salt-water. The largest pool had underwater viewing and the remaining six pools had above water viewing. Different configurations of pools were created by open and closed gates. Trainers varied the composition of the beluga social groupings several times during a day.

Table 1

\begin{tabular}{|c|c|c|c|c|c|c|c|}
\hline \multirow[t]{2}{*}{ Animal } & \multirow[t]{2}{*}{ Sex } & \multirow[t]{2}{*}{ Age (yrs) } & \multicolumn{5}{|c|}{ \# Sessions per social grouping } \\
\hline & & & Adults & $\begin{array}{l}\text { Adults- } \\
\text { Juveniles }\end{array}$ & $\begin{array}{l}\text { Mother- } \\
\text { Calf Pairs }\end{array}$ & $\begin{array}{c}\text { Mother- } \\
\text { Calf- } \\
\text { Juveniles }\end{array}$ & Mixed \\
\hline Adult 1 & M & $30 \mathrm{~s}$ & 8 & 25 & 0 & 0 & 48 \\
\hline Adult 2 & $\mathrm{~F}$ & $30 \mathrm{~s}$ & 6 & 27 & 0 & 0 & 50 \\
\hline Adult 3 & $\mathrm{~F}$ & Late $20 \mathrm{~s}$ & 5 & 22 & 0 & 0 & 37 \\
\hline Adult 4 & $\mathrm{~F}$ & Late $20 \mathrm{~s}$ & 0 & 1 & 23 & 22 & 63 \\
\hline Adult 5 & $\mathrm{~F}$ & $12-14$ & 0 & 1 & 24 & 23 & 46 \\
\hline Juvenile 6 & M & $5-7$ & 0 & 30 & 0 & 25 & 51 \\
\hline Juvenile 7 & $\mathrm{~F}$ & $3-5$ & 0 & 0 & 0 & 16 & 55 \\
\hline Juvenile 8 & $\mathrm{~F}$ & $2-4$ & 0 & 16 & 7 & 21 & 57 \\
\hline Calf 9 & M & Birth-2 & 0 & 0 & 24 & 8 & 17 \\
\hline Calf 10 & $\mathrm{~F}$ & Birth-2 & 0 & 0 & 23 & 6 & 18 \\
\hline
\end{tabular}

Note. Age represents the age of animals during the years of study (2012-2015). Adult 5 and all juvenile belugas and calves were born and reared at the study facility.

\section{Sample}

Since 2007, video recordings of beluga behaviors have been collected at different times of the day, two to three times a week, for 15 to $20 \mathrm{~min}$. The video recordings were collected using a focal follow procedure for mother-calf pairs or a scan sample method for each different social grouping. Video recordings were conducted when trainers were absent from the pool area to control for the influence of the trainers on the behaviors of the animals. For the current study, 175 videos were randomly selected from a set of 1500 to evaluate five specific social groupings. The availability of video recordings of the different social groupings determined the number of videos selected for each social grouping category. Five main social groupings were identified (Table 1 specifies number of sessions individual animals were present): adults only ( $n=13$, number of belugas ranged between $2-3)$, adults with a juvenile $(n=28$, number of belugas ranged between $3-5)$, mother-calf pairs $(n=24$, number of belugas ranged between $2-5)$, mother- 
calf pairs with a juvenile ( $n=26$, number of belugas ranged between $3-5$ ), belugas mixed, which included adults, mother-calf pairs, and juvenile animals ( $n=84$, number of adults ranged between $2-8)$.

\section{Measures}

Each video was initially coded for seven different behavioral categories: mother-calf swim, solitary swim, pair swim, affiliative interaction, sexual interaction, agonistic interaction, and play activity. Four of these categories (pair swim, affiliative interaction, sexual interaction, and agonistic interaction) were then combined to define a "social interaction." An eighth category captured time when the animals were not visible. Table 2 summarizes the operational definition for each behavior of interest.

Table 2

\section{Behavioral Categories and Operational Definitions}

\begin{tabular}{|c|c|c|}
\hline Behavioral Category & Operational Definition & Examples \\
\hline Mother-calf swim & $\begin{array}{l}\text { the calf and the mother swim in close } \\
\text { proximity (within } 2 \text { adult body lengths) } \\
\text { to one another }\end{array}$ & \\
\hline Solitary swim & $\begin{array}{l}\text { a beluga swims or floats independently, } \\
\text { or engages in independent behaviors }\end{array}$ & vocals, spy hops \\
\hline Pair swim & $\begin{array}{l}\text { two animals, swim in close proximity } \\
\text { (within } 2 \text { adult body lengths) from one } \\
\text { another, in which no contact occurs }\end{array}$ & \\
\hline Affiliative interaction & $\begin{array}{l}\text { two or more animals exchange } \\
\text { behavioral responses within proximity } \\
\text { in a positive or playful manner, during } \\
\text { which no agonistic behaviors are } \\
\text { present }\end{array}$ & \\
\hline Sexual interaction & $\begin{array}{l}\text { two or more animals exchange } \\
\text { behavioral responses within proximity, } \\
\text { during which genital presentation } \\
\text { and/or genital contact from the initiator } \\
\text { at the receiver is usually present }\end{array}$ & $\begin{array}{l}\text { horizontal s-postures, lateral } \\
\text { presentation with one pectoral fin out of } \\
\text { the water, pelvic thrusts, genital rubs }\end{array}$ \\
\hline Agonistic interaction & $\begin{array}{l}\text { two or more animals exchange } \\
\text { behavioral responses within proximity, } \\
\text { that are considered threatening or } \\
\text { harmful }\end{array}$ & $\begin{array}{l}\text { head jerks, open mouth threats, jaw } \\
\text { pops, bubble bursts }\end{array}$ \\
\hline Play activity & $\begin{array}{l}\text { a beluga interacts with an object within } \\
\text { the environment, manipulates water } \\
\text { with any part of the body, or engages in } \\
\text { body movements that are exaggerated } \\
\text { or involve atypical body positions }\end{array}$ & $\begin{array}{l}\text { includes trainer-provided toy, leaves, } \\
\text { bubbles, bubble rings, water spits, fluke } \\
\text { splashes, head stands, barrel rolls }\end{array}$ \\
\hline
\end{tabular}




\section{Procedure}

The videos selected for the sample were equally distributed among six different coders, who viewed and coded an equal number of videos from each social grouping category. The coders were trained by S. Guarino to code the videos through training sessions, during which they were taught to recognize the belugas and their behaviors. During training sessions the trainer and the coders practiced the coding process, using a 1-min point sampling rule. This coding technique required the coder to determine the most representative behavior of each animal in social grouping for each 1-min interval. Additionally, after the coders had independently coded the assigned videos, any unclear behavior observed by the coders was discussed during training sessions, and assigned to the most appropriate behavioral category.

To examine individual differences between the animals within a social grouping using the 1-min samples, the total number of occurrences of a given category was summed, divided by the number of intervals within a session for each animal per session, and then multiplied by 100 to attain the percentage. The session data were then averaged across each social grouping for each beluga per behavioral category to create an average percent of time in which a behavior was displayed in a social grouping by a beluga. To examine any behavioral differences between the different social groupings, the averages of the behavioral categories were averaged across all the animals within the session and converted to a percent. The averaged value for each session was considered an independent sample as the data represented a composite of a session that was randomly selected with different social compositions and times of day collected on different days. Each dependent variable was evaluated for normality and homogeneity of variance. To assess the influence of social grouping, univariate analysis of covariance tests (ANCOVA) were conducted for each dependent variable of interest, holding the number of animals constant between the sessions. The number of animals in a social grouping was considered a covariate as number of animals differed across sessions and social groupings and previous research with other animals had suggested that larger social groupings were associated with more social interactions and overall activities (Brewer, Bellinger, Joshi, \& Kleven, 2014; Held \& Spinka, 2011).

\section{Results}

\section{Behavioral Differences between Social Groupings}

Solitary Swimming. A univariate analysis of covariance (ANCOVA) analyzed the differences in the degree of solitary swimming displayed by the different social groupings. As a significant covariate, number of animals was controlled in the final analysis, $F(1,169)=15.21, p<0.001$. The results indicated that the overall percentage of solitary swimming displayed was influenced by the social grouping, $F(4,169)$ $=17.88, p<0.001, \mathrm{n}_{\mathrm{p}}{ }^{2}=0.30$. As hypothesized, the results of post hoc tests indicated that significantly more solitary swimming occurred for social groupings with adult belugas only (adjusted $M=85.72 \%$, SEM $=6.31 \%$ ) or with adult and juvenile belugas (adjusted $M=85.19 \%, S E M=4.03 \%$ ), as compared to any other social grouping (mother-calf pairs with juvenile: adjusted $M=64.70 \%, S E M=4.12 \%$; mixed: adjusted $M=62.39 \%$, SEM $=2.40 \%$; mother-calf pairs: adjusted $M=39.73 \%, S E M=4.32 \%), p<0.05$ (Figure 1). Although not hypothesized, but not unexpected, mother-calf pairs exhibited the lowest significant percentage of solitary swimming as mothers were more likely to swim with their calves when grouped together with no other adults or juveniles present (adjusted $M=36.01 \%, S E M=2.82 \%$ ) (Figure 1). To verify this statement, a univariate analysis of covariance indicated that the degree of mother-calf swimming displayed by the beluga mother-calf pairs when grouped alone, with other adults, or with juveniles was significantly different, $F(4,169)=28.97, p<0.001, \mathrm{n}_{\mathrm{p}}{ }^{2}=0.41$. Post hoc tests indicated that significantly more mother-calf swimming occurred for the social grouping with mother-calf pairs only as compared to the social groupings with mother-calf pairs with juveniles only (adjusted $M=11.83 \%, S E M$ $=2.70 \%$ ), or with mother-calf pairs with adults and juveniles (adjusted $M=5.66 \%, S E M=1.57 \%$ ). 
Hill et al. 273

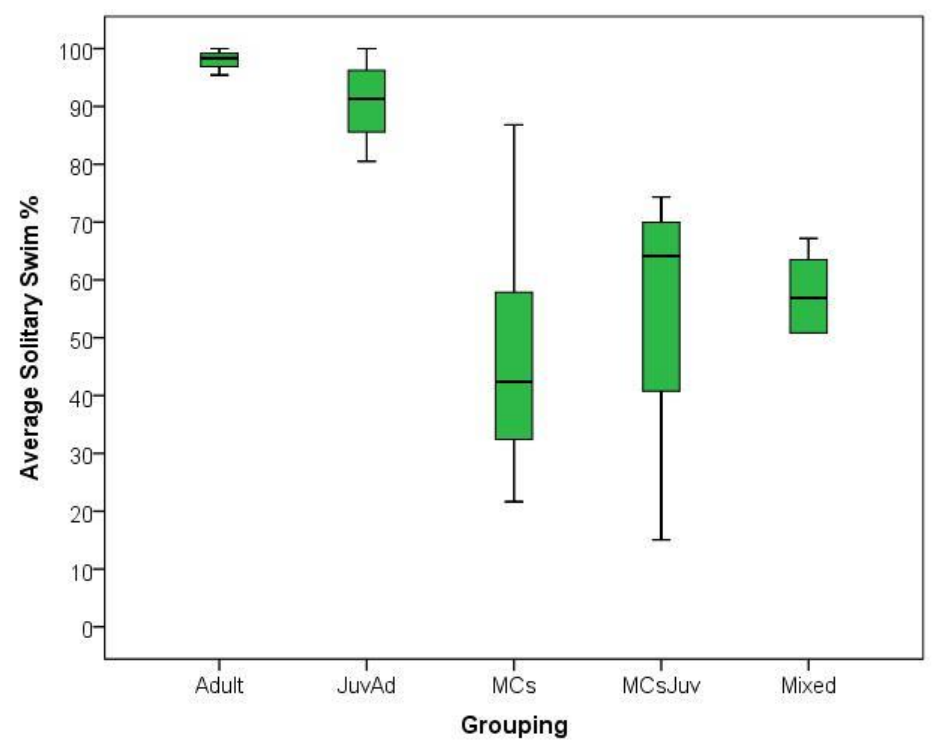

Figure 1. Boxplots of average solitary swim percentage per social grouping. Note the scale is a $100 \%$.

Play Activities. A univariate analysis of covariance (ANCOVA) analyzed the differences in the degree of play activities displayed by the different social groupings. As a significant covariate, number of animals was controlled in the final analysis, $F(1,169)=4.99, p=0.03$. The results indicated that the overall percentage of play activities displayed was influenced by the social grouping, $F(4,169)=4.54, p=0.002$, $\eta_{\mathrm{p}}{ }^{2}=0.10$. As hypothesized, the results of post hoc tests indicated that significantly less play activities occurred for the social grouping with adult belugas only (adjusted $M=-3.17 \%, S E M=3.70 \%$; actual $M=$ $0 \%$ ), and with adult and juvenile belugas (adjusted $M=2.84 \%, S E M=2.36 \%$ ), as compared to any other social grouping (mixed: adjusted $M=11.29 \%, S E M=1.40 \%$; mother-calf pairs: adjusted $M=10.05 \%$, $S E M=2.53 \%$; mother-calf pairs with juvenile: adjusted $M=9.82 \%, S E M=2.41 \%$ ), $p<0.05$ (Figure 2). These results support the predicted trend as significantly more play activities were observed within the social groupings in which the young belugas were present.

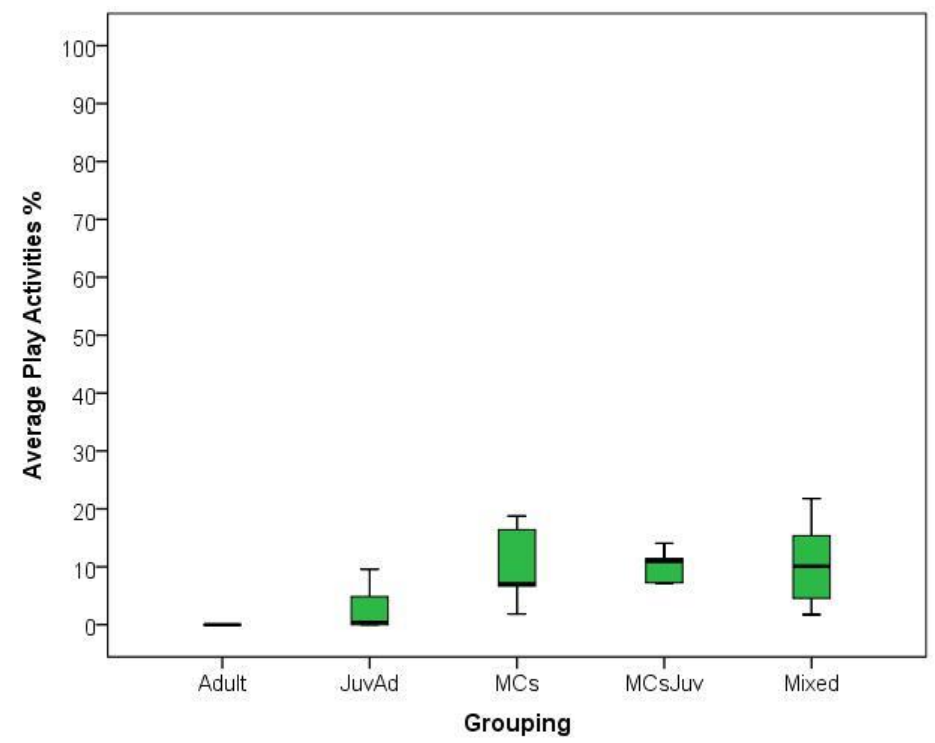

Figure 2. Boxplots of average play activities percentage per social grouping. Note the scale is a $100 \%$. 
Social interactions. A univariate analysis of covariance (ANCOVA) analyzed the differences in the degree of social interactions displayed by the different social groupings. For this behavioral category, the number of animals was not indicated as a significant covariate in the final analysis. Moreover, despite the variation in the social interactions between adult only social grouping $(M=3.69 \%, S E M=1.85 \%)$ and mother-calf pair social grouping $(M=7.54 \%, S E M=2.23 \%)$, the other social groupings were statistically similar (mother-calf pairs with juvenile: $M=6.57 \%, S E M=2.88 \%$; mixed: $M=4.66 \%, S E M=1.02 \%$; adults with juvenile: $M=3.00 \%, S E M=0.93 \%$ ). A follow-up analysis was performed in which the number of different categories of social interactions was coded for each session. A chi square test of independence was conducted to determine if there was a relationship between type of social grouping and the number of types of social interactions. The results indicated that both variables were independent of each other.

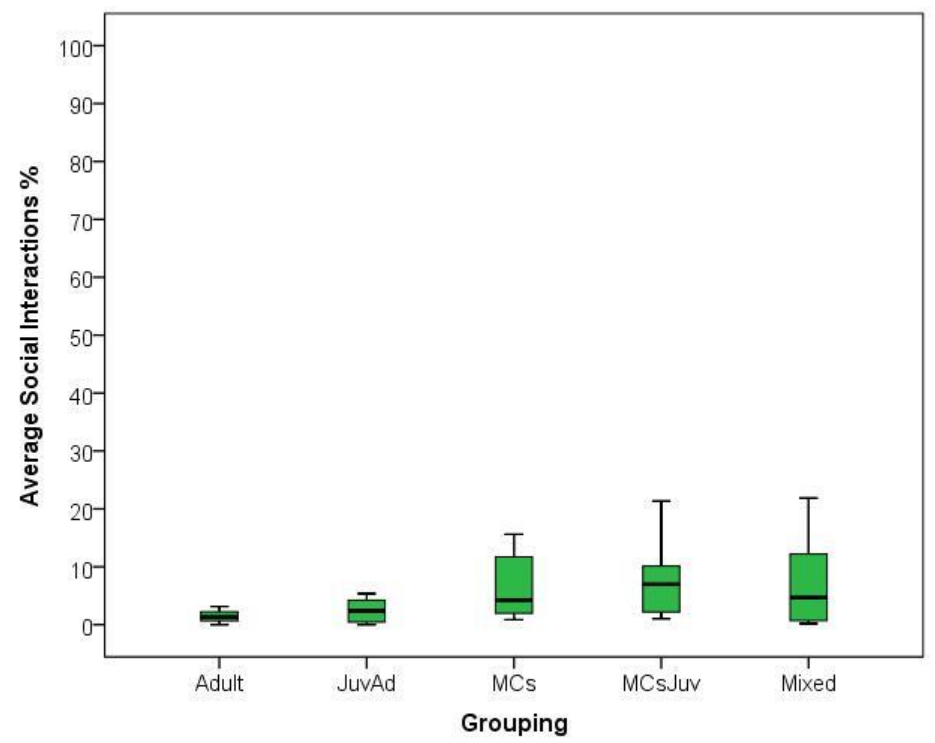

Figure 3. Boxplots of average social interactions percentage per social grouping. Note the scale is a $100 \%$.

Overall Activity. A univariate analysis of covariance (ANCOVA) analyzed the differences in the degree of overall activity displayed by the different social groupings when the averages of social interactions and play activities were combined. Although, the number of animals was not indicated as a significant covariate, the results indicated that the overall percentage of activity displayed was influenced by the social groupings, $F(4,169)=4.66, p=0.001, \eta_{p}^{2}=0.10$. As hypothesized, significantly less activities, involving social interaction and play occurred for the social groupings with adult belugas only $(M=3.69 \%, S E M=1.85 \%)$, or with the adult belugas and the juvenile $(M=6.70 \%, S E M=2.26 \%)$, as compared to any other social grouping (mother-calf pairs: $M=18.26 \%, S E M=3.34 \%$; mother-calf pairs with juvenile: $M=16.22 \%$, $S E M=3.46 \%$; mixed: $M=15.04 \%, S E M=1.46 \%$ ) (Figure 4). The findings supported the hypothesis that the percentage of time with which the adults engaged in activities involving social interaction and play increased when young belugas were present.

\section{Individual Results}

Solitary Swimming. As might be expected from the group results, the adult male (AM1) and two adult females without calves (AF2 and AF3) exhibited the greatest amount of solitary swimming on average (67\% - 76\%, Figure 5, Table 3). The two adult females with calves (AF4 and AF5) displayed solitary swimming less often on average and also displayed the greatest variation (54\% - 58\%, Figure 5, Table 2). The three juvenile belugas (JM6, JF7, and JF8) showed similar variation and slightly lower percentages of solitary swims than the adults $(63 \%-70 \%$, Figure 5, Table 2). Finally, the least amount of solitary swimming with the smallest variation were the two calves (CM9, 25\%; CM10, 22\%, Figure 5, Table 2). A 
Pearson's correlation indicated that age was positively correlated with average amount of solitary swimming, $r(30)=0.53, p=0.002$, indicating that the older belugas displayed more solitary swimming than the younger belugas.

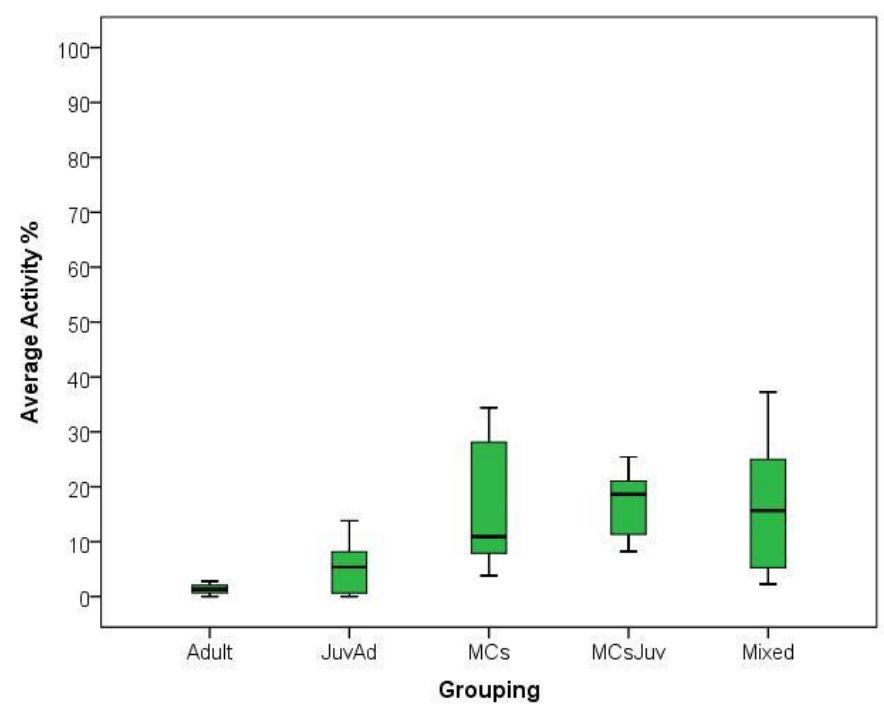

Figure 4. Boxplots of average overall activities percentage per social grouping. Note the scale is a $100 \%$.

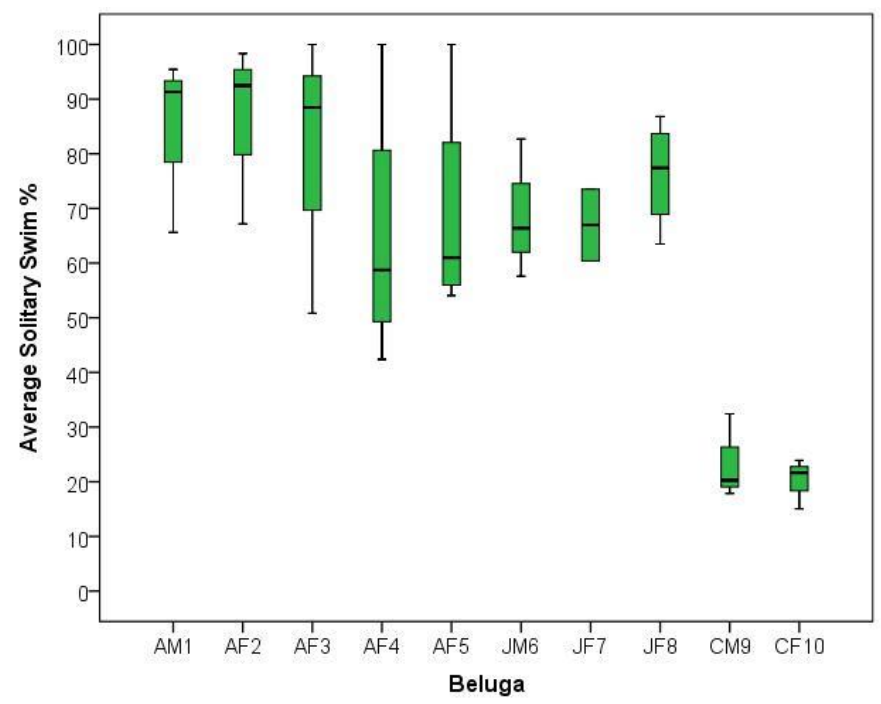

Figure 5. Boxplots of average solitary swim percentage per individual beluga. Note the scale is a $100 \%$.

Play Activities. As observed with the group results, play activities occurred at much lower levels than solitary swim for eight of the 10 belugas (exceptions: CM9, 15\% and CF10, 18\%, Figure 6, Table 2). While all the belugas showed some play activities, age was negatively associated with levels of play, $r(30)$ $=-0.73, p<0.001$. Thus, the older the beluga, the less the beluga played, on average (Figure 6). The adult male (AM1, 2\%) and the oldest adult female (AF2, 1\%) engaged in the least amount of play activities. The two adult females with calves (AF4, 7.5\% and AF5, 6\%) displayed the greatest variation in play activities as well as highest levels for adults. The juveniles and the calves engaged in similar levels of play, on average $(10 \%-18 \%)$. 
Table 3

Individual Descriptives per Behavioral Category per Social Grouping

\begin{tabular}{|c|c|c|c|c|c|c|c|c|c|c|}
\hline & \multicolumn{10}{|c|}{ Social Grouping } \\
\hline & \multicolumn{2}{|c|}{ ADULT } & \multicolumn{2}{|c|}{ AD/Juv } & \multicolumn{2}{|c|}{ MCs } & \multicolumn{2}{|c|}{ MCsJuv } & \multicolumn{2}{|c|}{ MIXED } \\
\hline & $M$ & $S D E$ & $M$ & $S D E$ & $M$ & $S D E$ & $M$ & $S D E$ & $M$ & $S D E$ \\
\hline \multicolumn{11}{|l|}{ Solo Swim } \\
\hline AM1 & 95.42 & 3.39 & 91.33 & 2.45 & & & & & 65.62 & 4.85 \\
\hline $\mathrm{AF} 2$ & 100.00 & 0.00 & 88.48 & 2.98 & & & & & 50.83 & 5.76 \\
\hline $\mathrm{AF} 3$ & 98.33 & 1.67 & 92.47 & 2.74 & & & & & 67.19 & 4.89 \\
\hline $\mathrm{AF} 4$ & & & & & 42.37 & 5.69 & 61.27 & 8.19 & 56.16 & 3.81 \\
\hline AF5 & & & & & 57.86 & 6.24 & 64.14 & 7.07 & 54.08 & 5.09 \\
\hline JM6 & & & 82.71 & 4.26 & & & 66.40 & 6.28 & 57.61 & 4.50 \\
\hline JF7 & & & & & & & 73.51 & 7.82 & 60.42 & 3.66 \\
\hline JF8 & & & 80.51 & 6.20 & 86.83 & 5.85 & 74.33 & 6.74 & 63.49 & 3.45 \\
\hline CM9 & & & & & 32.41 & 5.55 & 20.28 & 6.58 & 17.86 & 5.26 \\
\hline CF10 & & & & & 21.65 & 4.41 & 15.05 & 6.77 & 23.91 & 6.00 \\
\hline \multicolumn{11}{|l|}{ Play Activities } \\
\hline AM1 & 0.00 & 0.00 & 0.00 & 0.00 & & & & & 3.28 & 1.53 \\
\hline $\mathrm{AF} 2$ & 0.00 & 0.00 & 3.96 & 2.08 & & & & & 4.86 & 1.85 \\
\hline AF3 & & & 0.40 & 0.28 & & & & & 1.75 & 0.67 \\
\hline $\mathrm{AF} 4$ & & & & & 1.84 & 1.09 & 7.19 & 3.18 & 9.88 & 2.52 \\
\hline AF5 & & & & & 7.00 & 2.95 & 7.29 & 3.26 & 4.56 & 1.86 \\
\hline JM6 & & & 5.73 & 2.45 & & & 14.07 & 5.00 & 10.31 & 2.95 \\
\hline JF7 & & & & & & & 11.16 & 5.77 & 13.89 & 3.36 \\
\hline JF8 & & & 9.58 & 5.14 & 6.67 & 3.08 & 10.96 & 4.61 & 16.28 & 3.11 \\
\hline CM9 & & & & & 18.76 & 4.83 & 0.69 & 0.69 & 15.37 & 5.88 \\
\hline CF10 & & & & & 16.41 & 4.88 & 11.65 & 5.45 & 21.78 & 6.05 \\
\hline \multicolumn{11}{|c|}{ Social Interactions } \\
\hline AM1 & 3.13 & 2.49 & 5.35 & 1.99 & & & & & 10.07 & 2.64 \\
\hline $\mathrm{AF} 2$ & 1.33 & 1.33 & 2.40 & 1.05 & & & & & 0.18 & 0.18 \\
\hline AF3 & & & 0.86 & 0.50 & & & & & 0.53 & 0.25 \\
\hline AF4 & & & & & 1.97 & 1.05 & 1.03 & 0.84 & 0.70 & 0.34 \\
\hline AF5 & & & & & 0.88 & 0.88 & 1.19 & 1.00 & 0.72 & 0.47 \\
\hline JM6 & & & 4.21 & 1.40 & & & 11.37 & 4.20 & 14.66 & 2.99 \\
\hline JF7 & & & & & & & 8.86 & 3.86 & 7.67 & 1.70 \\
\hline JF8 & & & 4.24 & 2.09 & 4.24 & 2.20 & 3.22 & 1.82 & 1.71 & 0.50 \\
\hline CM9 & & & & & 15.64 & 4.90 & 21.36 & 11.89 & 21.87 & 6.17 \\
\hline CF10 & & & & & 11.71 & 3.69 & 6.99 & 5.07 & 12.21 & 4.28 \\
\hline \multicolumn{11}{|c|}{ Overall Activities } \\
\hline AM1 & 3.13 & 2.49 & 5.35 & 1.99 & & & & & 13.36 & 2.88 \\
\hline $\mathrm{AF} 2$ & 1.33 & 1.33 & 6.36 & 2.27 & & & & & 5.05 & 1.86 \\
\hline AF3 & & & 1.27 & 0.55 & & & & & 2.28 & 0.83 \\
\hline AF4 & & & & & 3.81 & 1.40 & 8.22 & 3.30 & 10.58 & 2.51 \\
\hline
\end{tabular}


Hill et al. 277

\begin{tabular}{|c|c|c|c|c|c|c|c|c|}
\hline AF5 & & & 7.88 & 2.99 & 8.48 & 3.51 & 5.27 & 1.89 \\
\hline JM6 & 9.94 & 2.89 & & & 25.44 & 5.94 & 24.97 & 3.90 \\
\hline JF7 & & & & & 20.02 & 6.34 & 21.56 & 3.41 \\
\hline JF8 & 13.83 & 6.21 & 10.91 & 4.64 & 14.18 & 4.97 & 17.99 & 3.15 \\
\hline CM9 & & & 34.40 & 6.32 & 22.06 & 11.73 & 37.24 & 7.16 \\
\hline CF10 & & & 28.12 & 5.97 & 18.64 & 7.57 & 33.99 & 31.39 \\
\hline
\end{tabular}

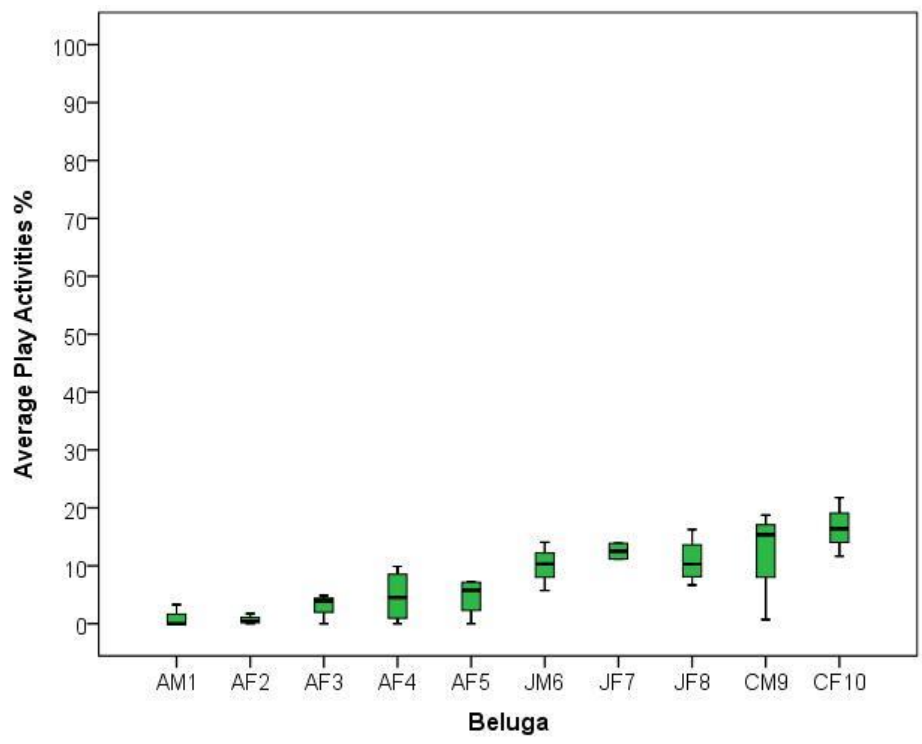

Figure 6. Boxplots of average play activities percentage per individual beluga. Note the scale is a $100 \%$. 
Social Interactions. As observed with the group results, social interactions also occurred at very low levels, especially for the adult females $(0.6 \%-1 \%$, Figure 7 , Table 2$)$. Again, all the belugas showed some social interactions, but the level of play was negatively associated with age of the beluga, $r(30)=$ $-0.62, p<0.001$. Thus, the older the beluga, the less the beluga interacted with others, on average (Figure 7). Interestingly, the belugas that showed the greatest means and variation were the three male belugas, an adult (AM1, 8\%), a juvenile (JM6, 11\%), and a calf (CM9, 19\%), all of which happened to interact with each other frequently. Clearly, the female calf (CF10, 11\%) also engaged in similar levels of social interactions as the males, but was most similar to the juvenile male.

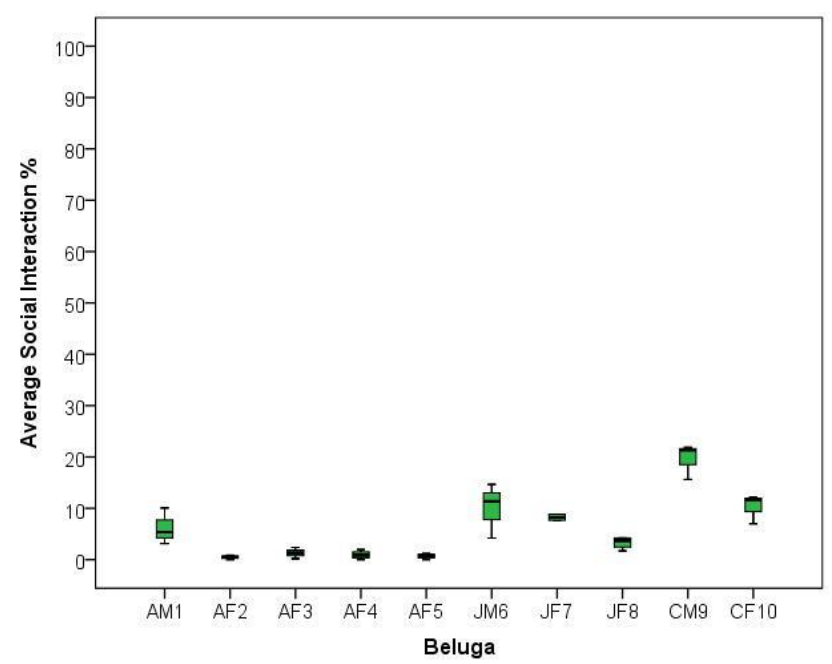

Figure 7. Boxplots of average social interactions percentage per individual beluga. Note the scale is a $100 \%$.

Overall Activity. Finally, when the overall activity levels were investigated, a negative correlation between age and level of activity was again found, $r(30)=-0.78, p<0.001$. Specifically, the adults did not display as much activity overall as the younger belugas, JM6 (21\%), JF7 (21\%), JF8 (16\%), CM9 (33\%), and CF10 (29\%) (Figure 8, Table 2). Interestingly, the belugas that showed the greatest means and/or variation in overall activity were the two older male belugas, the two youngest belugas (CM9 and CF10), and the two juvenile females (JF7 and JF8). The two adult females without calves (2\%-5\%) showed much less activity overall, on average, than the two adult females with calves (7-9\%) (Figure 8).

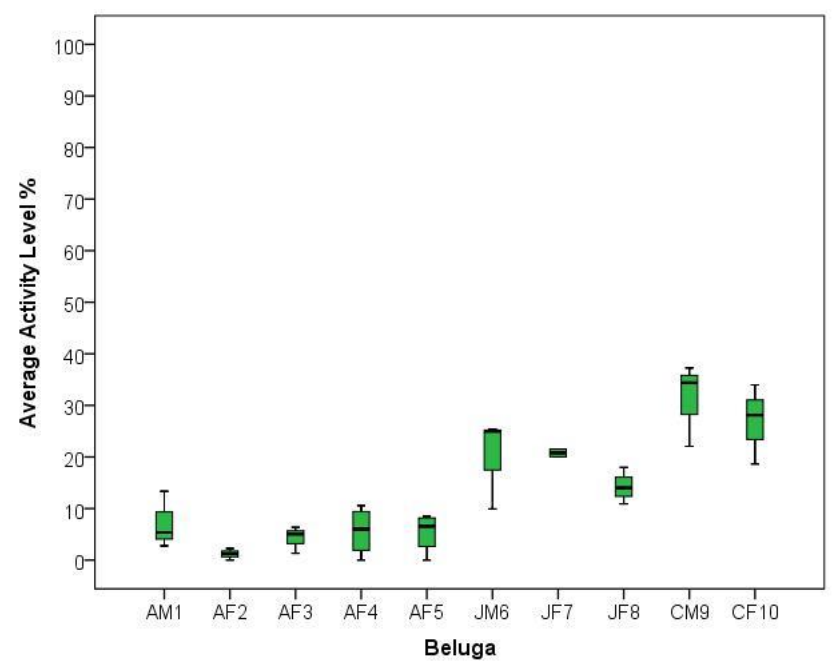

Figure 8. Boxplots of average overall activities percentage per individual beluga. Note the scale is a $100 \%$. 


\section{Discussion}

Environmental enrichment is intended to promote the physical and psychological well-being of animals in human care. One way to elicit spontaneous behaviors from the species-typical repertoire is to create social groupings that simulate natural groups or are compatible groups (Boere, 2001; Held \& Spinka, 2011; Hutchinson et al., 2005; Schapiro et al., 1996; Stoinski et al., 2004a, 2004b, 2013). When enriching, social groupings diversify the behavioral repertoires of individual animals by promoting different types of behaviors, including social interactions and play activities. Adult squirrel monkeys exhibited more affiliative social interactions when grouped with each other than when young offspring were present (Soltis et al., 2003). These results suggested that the composition of the social grouping was dependent upon age and a larger social grouping was not better. In contrast, guinea pigs, Cavia porcellus, engaged in more social interactions and general behaviors when housed in herds within open fields as opposed to standard pairs in a typical home cage (Brewer et al., 2014), suggesting that number of conspecifics did influence the diversity of the behavior within the overall group when supported by an appropriate physical environment. Research with western lowland gorillas also suggests that social composition can promote speciesappropriate and diverse behavior when males are introduced as juveniles and later housed together as a bachelor herd (Stoinski et al., 2004a, 2004b, 2013).

The results of the current study supported the premise that social grouping may also be used as an enrichment tool for captive marine mammals. Although retrospective in nature, and thereby limiting any conclusions about the direction of causality, the behavior of adult belugas was different when grouped with only other adults as opposed to when young conspecifics were part of the adults' social grouping. This conclusion is based upon several different behaviors (solitary swims, affiliative interactions, which included pair swimming, play activities, and social interactions of all types) rather than the full behavioral repertoire as a point sampling method was implemented for the study and not a continuous sampling method (Martin \& Bateson, 1993).

\section{Solitary Swimming, Social Interactions, and Play Activities}

Using this approach, we expected adults to reduce the percentage of solitary swimming from when they were grouped together to when they were grouped with young conspecifics. Solitary swimming in belugas is a typical behavior that may represent a resting behavior as seen with bottlenose dolphins (e.g., Sekiguchi et al., 2006). Resting behavior and solitary swimming are expected even in enriched environments, but may be indicative of a less enriching environment if performed too often (Mason, 2010; Swaisgood \& Shepherd, 2005). When the different social compositions were evaluated for solitary swimming, the adult belugas swam independently almost the entire session, on average, when grouped together (Figure 1). However, when one to two juvenile belugas were added to adult social groupings time the adults spent in solitary swimming dropped, although not significantly. Solitary swimming dropped the most when adults were grouped with multiple calves and juveniles, suggesting that the inclusion of immature belugas altered the overall time the adults spent in solitary swims (Figure 1). Also as expected, the adults increased, although not significantly, their play activities and social interactions, presumably due to the presence of one to two juvenile belugas (Figures 2 and 3). A descriptive examination of the social interactions and play activities indicated that the adult male interacted with the juvenile male while the adult females did not when grouped with the juvenile belugas. Interestingly, play activities increased for the adult male and female belugas when the juvenile belugas were present as indicated by the individual results (Figure 2). This pattern of results was magnified when the adults were grouped with young belugas of all ages (i.e., $1-7$ years, Figure 2). Interestingly, the reduced solitary swimming (Figure 1) was not replaced necessarily with a corresponding increase in social interactions (Figure 3), which was unexpected based on results from other animals (Brewer et al., 2014; Soltis et al., 2003). A follow-up analysis in which the different types of interactions were examined across the different social groupings did not support a diversification in social interactions as was expected if social groupings were enriching (Newberry, 1995; Swaisgood \& Shepherdson, 2005). It is possible that the apparent lack of diversity may have been related 
to the 1-min point sample method used to code the sessions as social interactions do not occur as frequently between belugas as other cetaceans, and when belugas do interact, they do not last as long as play activities and swims (Hill et al., 2015; Hill \& Ramirez, 2014) and may have been under-represented (Martin \& Bateson, 1993).

In contrast to the social interactions, the percentage of play activities did differ significantly by social grouping with adults displaying almost no play activities when together versus social groupings with mixed groups, which had levels of play similar to mothers and their calves or mothers, calves, and the juvenile male (Figure 2). As discussed by Held and Spinka (2011), contagious play seems to have a significant role in social groupings composed of mixed aged conspecifics. Specifically, younger conspecifics are more likely to play and may encourage adults to play more than is typical through a variety of social learning mechanisms, such as stimulus enhancement or imitation (Bekoff \& Byers, 1998; Held \& Spinka, 2011). It is likely that the adult belugas were influenced to engage in play activities by observing the play behaviors of the younger belugas. A review of the session data indicated that calves and adults displayed play behaviors within the same sessions, supporting the interpretation that the play activities of the young belugas may have influenced the play activities of adult belugas. Future research should examine the influence of social learning on the play activities of belugas and the frequency with which calves influence adults and adults influence the calves (e.g., Kuczaj et al., 2006).

Overall, when the play activities were combined with the social interactions, the significant trend for social grouping continued (Figure 4). Belugas displayed higher levels of activity during mixed social groupings, which always included immature belugas, than when adults only were together. This result along with the other findings was consistent when number of animals present was controlled. Previously, group size had produced mixed results with some animals responding with increased social interactions and activities with larger group sizes (e.g., guinea pigs, Brewer et al., 2014) and others not (e.g., meerkats, Suricata suricatta, Sharpe, 2005). Given the possible confound of group size, we selected to control for this variable in our analyses. Thus, all of the results suggesting that group composition influenced broad categories of beluga behavior may be interpreted without the confound of group size. As we learn more about the degree of sociality of belugas, we may find that social interactions may be influenced more by the participating belugas than by an overall number of social interactions. That is, our initial research indicated that calves were particularly sociable with their mothers and other calves, whereas adults did not appear to be as sociable (Hill, 2009; Hill \& Campbell, 2014; Hill, Campbell, Dalton, \& Osborn, 2013, unpublished data). However, this conclusion may be dependent upon the sex of the adult as research on the socio-sexual behaviors of belugas across several facilities has suggested that male-male interactions are particularly frequent and may be integral for long-term associations (Glabicky, DuBrava, \& Noonan, 2010; Hill et al., 2015). Future research needs to validate these observations with belugas in their natural habitat.

\section{Individual Results}

To better understand the trends that were observed at the group level for each social grouping, we also examined the responses of each beluga in the different social groupings and overall. Solitary swims of all adult animals without calves clearly decreased as they were grouped with younger belugas (Table 2). Solitary swims were lower for females with unweaned calves and for the calves themselves (Table 2). These patterns are expected as mothers and calves spend the majority of their time swimming together (Table 2, Hill, 2009; Hill \& Campbell, 2014; Hill et al., 2013).

The patterns for social interactions and play activities showed a wider range of variability across individuals. The adults without calves, and particularly the male, showed the greatest variability in their social interactions across the different social groupings (Figure 7 and Table 2). When grouped solely with each other, social interactions and play activities were almost non-existent. The social interactions that did occur during the adult only grouping were exhibited by the adult male and involved calves that were housed in the pool adjacent to the adults. Interestingly, when juveniles, particularly the male juvenile, were grouped with the adults the majority of the social interactions occurred between the two males and typically involved socio-sexual behaviors. An examination of the mothers and their calves showed the highest levels of social 
interactions occurred most frequently between mother-calf pairs followed by calf-calf pairs. A review of the data suggested that most of the interactions were affiliative in nature ( $8 \%$ as compared to agonistic and sexual combined $=<1 \%$ ). When the juvenile male was housed with the mother-calf pairs, social interactions increased slightly for the calves and decreased for the mothers suggesting that the calves shifted their attention to the juvenile male when he was present (Figure 7, Table 2). Finally, when the adult belugas were mixed with the immature belugas the male adult beluga was involved in more social interactions than the adult females with most of the interactions occurring with the juvenile male or the calves. The nature and frequency of social interactions are virtually unknown for belugas in their natural habitat, with the exception of mother-calf pairs (Krasnova, Bel'kovich, \& Chernetsky, 2006, 2009). Although many of the interactions and behaviors observed at the current facility have also been recorded at several other facilities, research with beluga populations in their natural habitat is necessary for greater generalizability of findings from captive populations.

When the play activities were considered for each beluga, it was clear that all the belugas played but at differing levels. Adult belugas, including the females with calves, rarely played whereas the juvenile and calves were more likely to exhibit play activities. Many of these play activities involved environmental enrichment devices (EEDs), natural-occurring objects, like sticks, leaves, or gates, and motor play, including barrel rolls or vertical spins. As demonstrated by Figure 6 and a positive correlation between age and play percentages, calves clearly showed the greatest range and highest levels of play across all types of social groupings. However, when the adults were examined individually, all adults increased their variation in time spent in play activities when mixed with calves, possibly supporting the role of contagious play (Table 2, Figure 6; Held \& Spinka, 2011).

\section{Summary}

The goal of the current study was to determine if the inclusion of immature belugas within a social grouping of belugas could be enriching to adults. The results strongly suggest that adult behavior changed such that it became more diverse in the overall behaviors exhibited when the adults were grouped with younger animals. Adult belugas displayed less solitary swimming and greater overall activity, including social interactions and play activities, when grouped with younger animals as opposed to each other. Future studies should include a prospective, experimental study in which individual behavioral repertoires are assessed to determine more definitive answers regarding the degree to which social compositions are actually enriching for belugas. Moreover, research on the wellbeing of captive animals should continue to be examined at both the population level and the individual level as pertinent information is gleaned from both levels of analysis (Clubb \& Mason, 2002; Mason \& Veasey, 2010).

\section{Acknowledgments}

We would like to thank SeaWorld San Antonio for their support of this study. This article represents Technical Contribution Number 2015-02-T for SeaWorld scientific publications. We would also like to thank all of the research assistants who collected the archived footage and who coded the data for this study, including Selena Garza, Mariyah McKinnon, Domonique Ramirez Wilson, Kristy Zuniga, Duffy Pitlock, Isabel Ramos-Garcia, Leo Reyes, Xyruz Villariz, Megan Medrano, Mahum Ijaz, Maggie Banda, and Diamantha Esquivel.

\section{References}

de Azevedo, C. S., Cipreste, C. F., \& Young, R. J. (2007). Environmental enrichment: A GAP analysis. Applied Animal Behaviour Science, 102, 329-343.

Bekoff, M., \& Byers, J. A. (1998). Animal play: Evolutionary, comparative, and ecological approaches. New York: Cambridge University Press.

Boere, V. (2001). Environmental enrichment for neotropical primates in captivity. Ciencia Rural, 31, $543-551$. 
Brando, S. I. (2010). Advances in husbandry training in marine mammal care programs. International Journal of Comparative Psychology, 23, 777-791.

Brewer, J. S., Bellinger, S. A., Joshi, P., \& Kleven, G. A. (2014). Enriched open field facilitates exercise and social interaction in 2 strains of guinea pigs (Cavia porcellus). Journal of the American Association for Laboratory Animal Science: JAALAS, 53, 344-355.

Burghardt, G. M. (2005). The genesis of animal play. Cambridge, MA: MIT Press.

Burghardt, G. M. (2013). Environmental enrichment and cognitive complexity in reptiles and amphibians: Concepts, review, and implications for captive populations. Applied Animal Behaviour Science, 147, 286-298.

Carlstead, K., Mench, J. A., Meehan, C., \& Brown, J. L. (2013). An epidemiological approach to welfare research in zoos: The elephant welfare project. Journal of Applied Animal Welfare Science, 16, 319-337.

Carlstead, K., \& Shepherdson, D. (1994). Effects of environmental enrichment on reproduction. Zoo Biology, 13, 447458.

Castellote, M., \& Fossa, F. (2006). Measuring acoustic activity as a method to evaluate welfare in captive beluga whales (Delphinapterus leucas). Aquatic Mammals, 32, 325-333.

Clark, F. E. (2013). Marine mammal cognition and captive care: A proposal for cognitive enrichment in zoos and aquariums. Journal of Zoo and Aquarium Research, 1, 1-6.

Clubb, R., \& Mason, G. (2002). A review of the welfare of zoo elephants in Europe. Horsham, UK: Royal Society for the Prevention of Cruelty to Animals.

Connor, R. C. (2002). Ecology of group living and social behaviour. In A. R. Hoelzel (Ed.), Marine mammal biology: an evolutionary approach (pp. 353-360). Malden, MA: Blackwell Publishing.

Glabicky, N., DuBrava, A., \& Noonan, M. (2010). Social-sexual behavior seasonality in captive beluga whales (Delphinapterus leucas). Polar Biology, 33, 1145-1147.

Greene, W. E., Melillo-Sweeting, K., \& Dudzinski, K. M. (2011). Comparing object play in captive and wild dolphins. International Journal of Comparative Psychology, 24, 292-306.

Harley, H., Fellner, W., \& Stamper, A. (2010). Cognitive research with dolphins (Tursiops truncatus) at Disney's The Seas: A program for enrichment, science, education, and conservation. International Journal of Comparative Psychology, 23, 331-343.

Harlow, H. F., \& Harlow, M. (1962). Social deprivation in monkeys. Scientific American, 207, $136-146$.

Hayes, M. P., Jennings, M. R., \& Mellen, J. D. (1998). Environmental enrichment for amphibians and reptiles. In D. J. Shepherdson, J. D. Mellen, \& M. Hutchins (Eds), Second nature: Environmental enrichment for captive animals (pp. 205-235). Washington, D.C.: Smithsonian Institute Press.

Held, S. D., \& Špinka, M. (2011). Animal play and animal welfare. Animal Behaviour, 81, 891-899.

Herzing, D. L. (2005). Transmission mechanisms of social learning in dolphins: Underwater observations of freeranging dolphins in the Bahamas. Autour de l'ethologie et de la cognition animale, 185-194.

Hill, H. (2009). The behavioral development of two beluga calves during the first year of life. International Journal of Comparative Psychology, 22, 234-253.

Hill, H., \& Campbell, C. (2014). Allocare depends on social composition for belugas (Delphinapterus leucas) in human care. International Journal of Comparative Psychology, 27, 501-514.

Hill, H., Campbell, C., Dalton, L., \& Osborn, S. (2013). The first year of behavioral development and maternal care of beluga (Delphinapterus leucas) calves in human care. Zoo Biology, 32, 565-570.

Hill, H. M., Carder, D. A., \& Ridgway, S. H. (2009). Vigilance in female bottlenose dolphins (Tursiops sp.) before and after calving. International Journal of Comparative Psychology, 21, 35-57.

Hill, H., Dietrich, S., Yeater, D., McKinnon, M., Miller, M., Aibel, S., \& Dove, A. (2015). Developing an ethogram of sexual and socio-sexual behaviors of beluga whales in the care of humans. Animal Behavior and Cognition, $2,105-123$.

Hill, H., \& Ramirez, D. (2014). Adults play but not like their young: The frequency and types of play by belugas (Delphinapterus leucas) in human care. Animal Behavior and Cognition, 1, 166-185.

Hunter, S. A., Bay, M. S., Martin, M. L., \& Hatfield, J. S. (2002). Behavioral effects of environmental enrichment on harbor seals (Phoca vitulina concolor) and gray seals (Halichoerus grypus). Zoo Biology, 21, 375-387.

Hutchinson, E., Avery, A., \& VandeWoude, S. (2005). Environmental enrichment for laboratory rodents. ILAR journal, 46, 148-161.

Kastelein, R., Postma, J., \& Jennings, N. (2007). Feeding enrichment methods for Pacific walrus calves [electronic resource]. Zoo Biology, 26, 175-186.

Knutson, B., Burgdorf, J., \& Panksepp, J. (1998). Anticipation of play elicits high-frequency ultrasonic vocalizations in young rats. Journal of Comparative Psychology, 112, 65-73. 
Krasnova, V. V., Bel'kovich, V. M., \& Chernetsky, A. D. (2006). Mother-infant spatial relations in wild beluga (Delphinapterus leucas) during postnatal development under natural conditions. Biology Bulletin, 33, 53-58.

Krasnova, V. V., Bel'Kovich, V. M., \& Chernetskii, A. D. (2009). Formation of behavior in the White Sea beluga calf, Delphinapterus leucas, during early postnatal ontogenesis. Russian Journal of Marine Biology, 35, 5359.

Kuczaj, S., Lacinak, T., Fad, O., Trone, M., Solangi, M., \& Ramos, J. (2002). Keeping environmental enrichment enriching. International Journal of Comparative Psychology, 15, 127-137.

Kuczaj, S. A., Makecha, R., Trone, M., Paulos, R. D., \& Ramos, J. A. (2006). Role of peers in cultural innovation and cultural transmission: Evidence from the play of dolphin calves. International Journal of Comparative Psychology, 19, 223-240.

Mackey, A. D., Makecha, R. N., \& Kuczaj, S. A. II. (2014). The development of social play in bottlenose dolphins (Tursiops truncatus). Animal Behavior and Cognition, 1(1), 19-35.

Martin, P., \& Bateson, P. P. G. (1993). Measuring behaviour: an introductory guide. Cambridge, UK: Cambridge University Press.

Mason, G. J. (2010). Species differences in responses to captivity: stress, welfare and the comparative method. Trends in Ecology \& Evolution, 25, 713-721.

Mason, G. J., \& Veasey, J. S. (2010). How should the psychological well-being of zoo elephants be objectively investigated? Zoo Biology, 29, 237-255.

Melfi, V. (2013). Is training zoo animals enriching? Applied Animal Behaviour Science, 147, $299-305$.

Millman, S. T., Johnson, A. K., O'Connor, A. M., \& Zanella, A. J. (2009). Animal welfare and epidemiology-across species, across disciplines, and across borders. Journal of Applied Animal Welfare Science, 12, 83-87.

Newberry, R. C. (1995). Environmental enrichment: Increasing the biological relevance of captive environments. Applied Animal Behaviour Science, 44, 229-243.

Ramirez, K. (1999). Animal training: Successful animal management through positive reinforcement. Shedd Aquarium Society.

Schapiro, S. J., Bloomsmith, M. A., Suarez, S. A., \& Porter, L. M. (1996). Effects of social and inanimate enrichment on the behavior of yearling rhesus monkeys. American Journal of Primatology, 40, 247-260.

Sekiguchi, Y., Arai, K., \& Kohshima, S. (2006). Sleep behaviour: Sleep in continuously active dolphins. Nature, 441, E9-E10.

Sharpe, L. L. (2005). Play does not enhance social cohesion in a cooperative mammal. Animal Behaviour, 70, 551558.

Shepherdson, D. J., Mellen, J. D., \& Hutchins, M. (1998). Second nature: Environmental enrichment for captive mammals. Washington, DC: Smithsonian Institution Press.

Shimada, M., \& Sueur, C. (2014). The importance of social play network for infant or juvenile wild chimpanzees at Mahale Mountains National Park, Tanzania. American Journal of Primatology, 76, $1025-1036$. doi:10.1002/ajp.22289

Shyne, A. (2006). Meta-analytic review of the effects of enrichment on stereotypic behavior in zoo mammals. Zoo Biology, 25, 317-337.

Smith, B. P., \& Litchfield, C. A. (2010). An empirical case study examining effectiveness of environmental enrichment in two captive Australian sea lions (Neophoca cinerea). Journal of Applied Animal Welfare Science, 13, 103-122.

Soltis, J., Wegner, F. H., \& Newman, J. D. (2003). Adult cortisol response to immature offspring play in captive squirrel monkeys. Physiology \& Behavior, 80, 217-223. doi:10.1016/j.physbeh.2003.07.009

Stafne, G. M., \& Manger, P. R. (2004). Predominance of clockwise swimming during rest in Southern Hemisphere dolphins. Physiology \& Behavior, 82, 919-926.

Stoinski, T. S., Kuhar, C. W., Lukas, K. E., \& Maple, T. L. (2004a). Factors influencing the formation and maintenance of all-male gorilla groups in captivity. Zoo Biology, 23, 189-203.

Stoinski, T. S., Kuhar, C. W., Lukas, K. E., \& Maple, T. L. (2004b). Social dynamics of captive western lowland gorillas living in all-male groups. Behaviour, 141, 169-195.

Stoinski, T. S., Lukas, K. E., \& Kuhar, C. W. (2013). Effects of age and group type on social behaviour of male western gorillas (Gorilla gorilla gorilla) in North American zoos. Applied Animal Behaviour Science, 147, 316-323. doi:10.1016/j.applanim.2013.07.003

Swaisgood, R. R., \& Shepherdson, D. J. (2005). Scientific approaches to enrichment and stereotypies in zoo animals: What's been done and where should we go next? Zoo Biology, 24, 499-518.

Swaisgood, R., \& Shepherdson, D. (2006). Environmental enrichment as a strategy for mitigating stereotypies in zoo animals: A literature review and meta-analysis. In G. J. Mason \& J. Rushen (Eds.), Stereotypic Animal 
Behaviour: Fundamentals and Applications to Welfare (2nd ed., pp. 255-284). Wallingford, UK: CAB International.

Swaisgood, R. R., White, A. M, Zhou, X., Zhang, H., Zhang, G., Wei, R.,...Lindburg, D. G. (2001). A quantitative assessment of the efficacy of an environmental enrichment programme for giant pandas. Animal Behaviour, 61, 447-457.

Walker, M., Díez-León, M., \& Mason, G. (2014). Animal welfare science: Recent publication trends and future research priorities. International Journal of Comparative Psychology, 27, 80-100.

Wells, D. L. (2009). Sensory stimulation as environmental enrichment for captive animals: a review. Applied Animal Behaviour Science, 118, 1-11.

Whitham, J. C., \& Wielebnowski, N. (2013). New directions for zoo animal welfare science. Applied Animal Behaviour Science, 147, 247-260. 